УДК 821.161.1.0

DOI 10.23951/1609-624X-2020-3-14-21

\title{
ЦЕННОСТНО-СМЫСЛОВЫЕ АСПЕКТЫ ИЗУЧЕНИЯ АГИОГРАФИЧЕСКОЙ ТРАДИЦИИ В ТВОРЧЕСТВЕ Ф. М. ДОСТОЕВСКОГО: МЕТОДОЛОГИЧЕСКАЯ РЕФЛЕКСИЯ
}

\author{
А. Н. Кочечко, А. С. Шилова
}

Томский государственный педагогический университет, Томск

\begin{abstract}
Введение. Представлена методологическая рефлексия изучения ценностно-смысловых аспектов репрезентации агиографической традиции в творчестве Достоевского. Анализ художественной антропологии писателя, идейных поисков и духовных коллизий, определяющих особенности проблематики и поэтики его произведений, позволяет увидеть глубинную связь с агиографической традицией в ее понимании мира и человека. Духовный опыт, запечатленный в житиях, для писателя является не просто жанровым или изобразительным инструментом, а глубинным смысловым вектором, антропологической и аксиологической доминантой.

Материал и методы. Материалом исследования являются художественные и публицистические произведения позднего творчества Ф. М. Достоевского, эго-документы писателя, воспоминания современников. Методологической основой исследования является аксиологический подход, который носит комплексный характер и включает в себя культурно-исторический, сравнительно-сопоставительный, структурно-типологический и биографический аспекты.

Результаты и обсуждение. Репрезентация агиографической традиции неразрывно связана с мировоззрением писателя, его системой ценностей. В системе воззрений Ф. М. Достоевского вопросы о человеке, его духовном и нравственном развитии, ценностных установках и идеалах имеют большое значение, находят отражение в художественном творчестве, в особенности в романе «Братья Карамазовы» и «Житии Великого грешника», берут основу среди жизненных установок писателя, его религиозном воспитании и религиозно-философском мировосприятии.

Заключение. Влияние агиографической традиции на творчество Достоевского - комплексная проблема как с точки зрения аспекта исследования, так и с точки зрения методологии. В исследовании необходимо учитывать глубинную связь русской литературы с христианской религиозной традицией. В процессе смены литературных формаций творчество Достоевского позволяет увидеть то духовное ядро, которое сохраняет русская классическая литература и транслирует из эпохи в эпоху в качестве культурообразующей и смыслообразующей доминанты.
\end{abstract}

Ключевые слова: Ф. М. Достоевский, «Братья Карамазовы», «Житие Великого грешника», «Дневник писателя», эго-документы, автор, агиографическая традииия, аксиология, иенности, иенностно-мировоззренческая позиция, христианство, православие, русская культура, нравственность, духовность, святость, аксиологический подход.

\section{Введение}

Глубинная сущность антропологии Достоевского, нашедшая отражение в ценностно-смысловой структуре его произведений, воплощенная в образах героев, их трагических по своему характеру идейных поисках и духовных коллизиях, связана с постижением громадного целого, «нравственного закона», смысла истории [1, с. 142]. Именно сущность антропологии Достоевского позволяет увидеть глубинную связь с житийной традицией в ее понимании мира и человека, по сути, говорить о понимании основного вектора жизни, устремленного ко Христу. Отсюда - постановка предельных экзистенциальных вопросов о мире и человеке, погружение автором своих героев и читателя в точки пройденного им самим мировоззренческого кризиca, обнажающего pro et contra, ценностные установки личности и субъективные смыслы ее существования, через встречу с которыми происходит обретение цельности и подлинности Я. Парадокс в том, что этот кризис на пороге небытия обнажает в герое (как и воспринимающем текст субъекте) идеальное начало, духовный вектор, высшие смысложизненные установки через ситуацию отпадения, отступничества, маргинализации, которая понимается и осознается как не-норма, не-идеал, не-спасение.

Эти идеи оказываются наиболее репрезентативно представленными в поздних произведениях Достоевского - итоговом романе Великого Пятикнижия «Братья Карамазовы» и связанном с ним «Житии Великого грешника», реализующем на уровне оксюморонного заглавия pro et contra как аксиологическую установку автора в изображении духовных и религиозно-философских доминант как поля явных и отчетливо осознаваемых ценностных антиномий, осмысление которых в своем предельном варианте выходит на уровень обобщений о судьбе России и русского народа, о православии, «мире с Богом» и «мире без Бога». Духовный опыт, запечатленный в агиографической традиции, становится не просто жанровым или изобразительным ин- 
струментом для писателя в решении вопросов о смысле человеческой жизни, об идеале и ценностном самоопределении человека, а глубинным смысловым вектором, антропологической и аксиологической доминантой художественной реальности, своеобразным камертоном, проверяющим характер и последствия сделанного личностью выбора, духовной логики движения к полюсу атеизма и абсурда или веры и созидания, подлинной цельности.

Нужно заметить, что сложившаяся в достоевсковедении практика исследования влияния житийной литературы на произведения писателя демонстрирует сосредоточенность преимущественно на анализе сюжетов и образов, использовании элементов жанровой модели жития в романном повествовании, текстовых перекличек, цитат и аллюзий, исследовании агиографических формул в характеристике героев или ориентации повествователя и т. д. В частности, В. Е. Ветловская отмечает наличие формул, характерных для агиографии, и интерпретирует жанровые особенности житийных мотивов в романе [2]. В. В. Кусков исследует проблему использования Достоевским в романе «Братья Карамазовы» текстов Евангелия, апокрифической литературы, выявляет в произведении характерные для русской агиографии сюжеты и образы [3]. Другие исследователи рассматривают проблему с точки зрения религиозной проблематики произведений писателя, решением важнейшего для писателя вопроса о вере в Бога, идеале святости, духовных доминантах русского Православия (работы Б. Н. Тихомирова [4], Т. А. Касаткиной $[5,6]$ и др.). Богословский аспект агиографической традиции в творчестве Достоевского исследует А. С. Ланцов в работе «Будут все как дети Божьи...», определяя произведения писателя как новую жанровую модель, которая соединяет в себе признаки жития и романа [7]. Классические работы К. В. Мочульского [8], Г. М. Фридлендера [9], В. С. Гроссмана [10] и др., посвященные биографии и особенностям творческого пути Достоевского, содержат ценный материал для понимания авторской позиции, эволюции замысла «Братьев Карамазовых» и «Жития Великого грешника», культурно-исторического контекста, оказавшего влияние на автора, но не содержат упоминаний об обращении к произведениям житийной традиции и древнерусской словесности в целом, что стало бы значимым фактографическим ресурсом в изучении темы и было осмыслено исследователями значительно позже в силу идеологической ситуации и невозможности на определенном этапе развития достоевсковедения говорить о текстах и контекстах Православия в творческом наследии писателя и его мировоззренческой позиции [11].
Следовательно, для исследования агиографической традиции в творчестве Достоевского методологически значимо понимание того факта, что система ценностей древнерусских агиографов отличалась от ценностной системы писателя как человека пореформенной эпохи в своем главном основании - многомерности восприятия реальности с доминантой на духовных основаниях мировидения, религиозном мировоззрении. Необходимо учитывать, что агиография как феномен древнерусской словесности имела сакральный характер, была связана с богослужебной практикой и практикой личного духовного подвига мирян, поэтому не ограничивалась сферой художественной литературы, поскольку по своему характеру таковой в чистом виде не являлась. Именно религиозно-богословский фундамент, предполагающий не только интеллектуальное и эстетическое, но и духовное переживание, определяет ценностно-смысловую структуру жития и методику его изучения и как самостоятельного жанра, и как факта агиографической традиции, которую вбирает в себя творчество Достоевского. В этой логике аксиологический подход представляется нам наиболее продуктивным и аутентичным для исследования агиографической словесности в силу своего комплексного характера, позволяющего учитывать различные аспекты единого художественного целого. Как справедливо замечает по этому поводу Л. Г. Дорофеева, «любое разделение исследования объекта на аспекты изучения не означает их оторванности друг от друга. И литературно-филологическое изучение агиографии непременно включает в себя - как условие изучения текста - историко-богословский и социально-культурный аспекты, а также исторический, неотделимый, впрочем, от историко-богословского» $[12$, c. 14$]$.

\section{Материал и методы}

Материалом исследования являются художественные и публицистические произведения позднего творчества Ф. М. Достоевского (роман «Братья Карамазовы», «Житие Великого грешника», «Дневник писателя»), эго-документы писателя, воспоминания современников. Методологической основой исследования является аксиологический подход, который носит комплексный характер и включает в себя культурно-исторический, сравнительно-сопоставительный, структурно-типологический и биографический аспекты. Применение аксиологического подхода в данном случае позволяет расширить представления о генезисе и репрезентации агиографической традиции в творческом наследии Достоевского, исследовать личностнобиографический контекст и ценностно-мировоззренческую позицию писателя и художественную 
поэтику его произведений как способ репрезентации аксиологических доминант и вызовов пореформенной эпохи.

\section{Результаты и обсуждение}

Роман «Братья Карамазовы» - итоговое произведение писателя, квинтэссенция его творческого пути. Не случайно Великое Пятикнижие завершается текстом, который вбирает в себя образы, мотивы, сюжеты не только других романов цикла, осмысляя и репрезентируя их на качественно новом уровне, но и духовного опыта Достоевского как личности и как автора художественных и публицистических произведений, в центре которых - всегда человек в ситуации ценностного выбора в экзистенциальной позиции. Возможно, что именно в силу этой аксиологической и смысловой напряженности роман так и не был завершен писателем. Однако многие аспекты творческих и духовных поисков писателя в этот период определяет контекст: эго-документы (письма, наброски, записи), неосуществленный романный замысел «Житие Великого грешника», дошедший до нас в виде серии набросков в рабочих записях Достоевского. В частности, об идее этого произведения он сообщает в письмах к А. Н. Майкову и Н. Н. Страхову: «Этот роман я считаю моим последним словом в литературной карьере моей» ${ }^{1}$ (т. 29, с. 151); «Главный вопрос, который проведется во всех частях, - тот самый, которым я мучился сознательно и бессознательно всю мою жизнь, - существование Божие» (т. 29, с. 117).

«Пограничная ситуация» жизни, осознаваемая писателем и через призму своего опыта, и через призму жизни русской нации в целом, ориентирует писателя на поиск духовных ресурсов для преодоления мировоззренческого кризиса пореформенной эпохи, высших смысложизненных ориентиров, которые для писателя неразрывно связаны с ценностями русского Православия. Биографический контекст личной судьбы Достоевского, формирование ценностной структуры его сознания связаны с религиозным и воспитательным опытом православной традиции как духовным фундаментом личности еще с раннего детства, причем приобщение к этой традиции связано не только с живым религиозным опытом семьи, но и с текстами Священного Писания и житийной литературы: «Стремление родителей воспитать доброго, порядочного, самостоятельного человека предполагало создание духовного фундамента личности через раннее приобщение к религиозному опыту православия. $<\ldots>$ Большое значение в духовно-нравственном воспитании детей имели уроки „Закона Бо-

${ }^{1}$ Ссылки на источник [13] даются в круглых скобках с указанием тома и страницы. жьего“. Приходивший в дом Достоевских дьякон вдохновенно рассказывал истории Ветхого и Нового завета своим ученикам, в факты Священной истории пробуждали стремление к нравственному анализу собственных мыслей и поступков (здесь и далее в цитатах курсив наш. - $A$. K., A. Ш.). Показателен этот особый характер слова, дающий образец для подражания, выход в сферу надличностного бытия, трансцендентного идеала, и возможность для самоанализа и саморефлексии, осознания себя и своего «Я есмь» в бытии: «поэтический строй текста, сопрягающего в пределах каждого конкретного сюжета бытовое и сакральное содержание, пробуждал деятельный ум Достоевского-мальчика к активной рефлексивной деятельности, погружению в процессы внутреннего мира человека» [14, с. 51]. Цельность и естественность детских религиозных впечатлений, первичного духовного опыта в период взросления писателя становятся точкой поиска, серьезного метафизического кризиса, проверкой опытом жизни своих убеждений и ценностей, который завершается на каторге перерождением, сознательным приходом к вере и вырастает до целостной духовной позиции. В «Дневнике писателя», осмысляя этот опыт, Достоевский замечает: «А между тем я был, может быть, одним из тех (я опять про себя одного говорю), которым наиболее облегчен был возврат к народному корню, к узнанию русской души, к признанию духа народного. Я происходил из семейства русского и благочестивого. С тех пор как я себя помню, я помню любовь ко мне родителей. Мы в семействе нашем знали Евангелие чуть не с первого детства» (т. 21, с. 134).

Духовный вектор личности писателя, сформированный в контексте православного миропонимания, сознательно выбранный и присвоенный, определяет четкую иерархию ценностей: «Для Достоевского ценности - это не специфически социальное явление, а уровень духовной организации личности. Аксиологическая система экзистенциального сознания совершенно особая, а в случае Достоевского обусловленная спецификой личности (экзистенциальным мировидением, предельным ощущением „Пограничности“ бытия вообще, особым отношением к ценностям православной культуры, ценностной парадигме русской романтической традиции) и пореформенной эпохи (и опыта своего проживания в ней)» $[15$, с. 96]. В контексте изучения ценностно-смысловых аспектов агиографической традиции в творчестве Достоевского этот иерархический вектор «Бог, народ, семья, человек, сердце, Другой (Другие)» определяет стратегию исследования его личностной и писательской позиции, форм репрезентации этого ценностного ядра в проблематике и поэтике произведений, в самом феномене «пограничных жанров», синтетических жан- 
ровых форм романа-жития и романа-антижития, в художественной антропологии писателя.

Этот всепоглощающий характер антропологических поисков и экспериментов Достоевского становится не только объектом напряженной писательской рефлексии над своим собственным творчеством, но и фокусом ценностного анализа, проверки на способность выходить за пределы прагматики и социального опыта, устремляться в сферу идеала, чувствовать, понимать, распознавать его проявление в себе и Других. Именно об этом говорит Н. А. Бердяев, замечая, что «у Достоевского нет ничего. Кроме человека, нет природы, нет мира вещей, нет в самом человеке того, что связывает его с природным миром, с миром вещей, с бытом, с объективным строем жизни. Существует только дух человеческий, и только он интересен, он исследуется» [16, с. 264].

Достоевский ставит перед собой и читателем важнейший вопрос: что есть человек? И в поисках ответа на него говорит о глубинном и сущностном, о высших пределах человеческого существования, намеренно ставя своего героя в самые невероятные обстоятельства, подвергая его колоссальным духовным испытаниям. Писателю важны не сами по себе ситуации и события, в которых оказывается человек, а его мысли, сомнения, душевные муки, выбор, поступки: «Уникальность проявления экзистенциального начала в творчестве Достоевского заключается в том, что все вопросы, поставленные им и относительно собственной жизни, и относительно духовных поисков его героев, всегда напрямую связаны с постановкой и поиском путей решения центральной для писателя проблемы - проблемы человеческого существования» [17, с. 99].

Это исследование вопроса о человеке в ситуации предельного выбора и предельного духовного напряжения позволяет увидеть глубинную связь творчества Достоевского с житийной традицией в ее эсхатологической сути, эсхатологическом понимании мира и человека. Здесь необходимо сделать важную оговорку: романы писателя - это не стилизация à la житие, не слепое копирование житийного канона, который не приложим к реалистическому произведению. Мы понимаем, что древнерусский агиограф создавал свои тексты в соответствии с антропологической моделью, существенно отличающейся от воззрений и мироощущения человека XIX в., что ценностная структура сознания русского человека до XVII в. цельная и неразрывно связана с представлениями о вечности бытия, бессмертии души и духа: «Духовный облик древнерусского человека при реконструкции обнаруживает специфичность, несоотносимость с современными представлениями <..> Современный человек воспитан в контексте революционного и инновацион- ного мировоззрения, в то время как древний - в контексте традиционной культуры. Традиционалистская антропологическая доминанта Древней Руси органически входит в христианскую антропологию» [18, с. 245].

Но именно предельные вопросы о Христе, мире и человеке, проблема антропологического идеала, апокалиптичность и эсхатологичность сознания при всей разнице культурного и ценностного контекста сближают творческую позицию Достоевского с аксиологической парадигмой древнерусской агиографии.

Жития через набор этикетных ситуаций жизни и подвига святого, зафиксированных в строгом агиографическом каноне, формировали четкую ценностно-мировоззренческую позицию древнерусских читателей и слушателей, антропологический вектор, устремленный к идеалу святости, спасения души, давали представление о нравственности и реальной возможности реализации духовных ценностей через поступки и образ жизни человека [19, с. 103]. Как замечает Д. С. Лихачев, «древнерусскую литературу можно рассматривать как литературу одной темы и одного сюжета. Этот сюжет мировая история, и эта тема - смысл человеческой жизни». Причем мировая история в произведениях Древней Руси представлена не в социально-бытовой плоскости, а в своем величии и трагизме и «в центре ее находится жизнь одного лица - Христа» [20, с. 87]. Именно «сияющая личность» Христа, как ее определяет Достоевский, является идеалом православного человека, и этот идеал Древней Руси в определенной мере «наследуется» писателем в новой исторической ситуации в качестве духовной «точки сборки» распавшегося в пореформенную эпоху человеческого существования, стремительно погружающегося в антиценности и антибытие через сознательный отказ от традиционных ценностей русской культуры, ее духовного опыта, через атеизм, веру в «небытие Бога».

В общественной мысли второй половины XIX в. как представители разночинной интеллигенции, так и образованного большинства аристократии начинают открыто говорить о ложности ценностей русского Православия, как и любой другой традиционной религиозной доктрины. Сталкиваясь с подобными явлениями, Достоевский считал необходимым четко обозначать свою позицию: «Тут оставалась, однако, сияющая личность самого Христа, с которою всего труднее было бороться. Учение Христово он (про Белинского), как социалист, необходимо должен был разрушать, называть его ложным и невежественным человеколюбием, осужденным современною наукой и экономическими началами; но все-таки оставался пресветлый лик богочеловека, его нравственная недостижимость, 
его чудесная и чудотворная красота» (т. 21, с. 10). Несмотря на социальные эксперименты пореформенной эпохи, самоопределение «дитя неверия и сомнения», для писателя проблема идеала незыблемо остается в парадигме православного вероучения: «живет Бог в человеке, живет в человеке добро, несмотря на всю ту наносную грязь, которой покрывает он себя. <..>> Он именно образ Божий, но падший. Потому Достоевский и не произносит суда над грешником, что видит в нем искру Божию как залог его восстания и спасения» [21].

Для писателя идея спасения неразрывно связана с мессианской ролью русского народа, которая осталась в сознании народа неизменной со времен Древней Руси именно благодаря сохранению агиографической традиции: «Знает же народ Христа Бога своего, может быть, еще лучше нашего, хоть и не учился в школе. Знает, - потому что во много веков перенес много страданий и в горе своем всегда, с начала и до наших дней слыхивал об этом Боге-Христе своем от святых своих, работавших на народ и стоявших за землю русскую до положения жизни, от тех самых святых, которых чтит народ доселе, помнит имена их и у гробов их молится. Поверьте, что в этом смысле даже самые темные слои народа нашего образованны гораздо больше, чем вы в культурном вашем неведении об них предполагаете, а может быть, даже образованнее и вас самих, хоть вы и учились катехизису» (т. 22, с. 113). Эту мысль Достоевский развивает в «Дневнике писателя», определяя смысл древнерусской агиографии как духовного национального кода: «Народ наш чтит память своих великих и смиренных отшельников и подвижников, любит рассказывать истории великих христианских мучеников своим детям. Эти истории он знает и заучил, и я сам их впервые от народа услышал, рассказанные с проникновением и благоговением и оставшиеся у меня на сердце» (т. 25, с. 69).

Для Достоевского понятие святости является не условным качеством житийного героя, а несет в себе высшее сакральное значение, святой олицетворяет образец нравственного поведения. Достоевскому житие подсказало определенный способ понимания мира и человека. Писатель использует житийную формулу не просто как эстетическое явление, заключает в нее особое миропонимание, свою философию. В. С. Соловьев, современник Достоевского, в своих «речах» в память о Достоевском писал по этому поводу: «Окончательная оценка всей деятельности Достоевского зависит от того, как мы смотрим на одушевляющую его идею, на то, во что он верил и что любил. А любил он, прежде всего, живую человеческую душу во всем и везде, и верил он, что мы все род Божий, верил в бесконечную силу человеческой души, торжеству- ющую над всяким внешним насилием и над всяким внутренним падением. Приняв в свою душу всю жизненную злобу, всю тяготу и черноту жизни и преодолев все это бесконечной силой любви, Достоевский во всех своих творениях возвещал эту победу» [22, с. 61].

Специфика сознания Достоевского определяется тем, что он пытается выстроить систему ценностных ориентиров, «найти то «ядро», которое составляет неистребимую основу бытия и позволяет в «мировом вихре» сохранить «образ человека, образ народа и образ человечества для высшей творческой жизни»: он стремится восстановить в генетической и нравственной памяти людей Божий лик, поскольку мир без Бога неминуемо превращается в мир без человека» [23, с. 65].

\section{Заключение}

Завершая методологические размышления, необходимо акцентировать те принципиальные моменты, без которых невозможно аутентичное исследование влияния агиографической традиции на творчество Ф. М. Достоевского:

1. Ценностно-смысловую основу русской литературы, ее глубинную смысловую структуру определяет евангельское слово и христианская религиозная традиция, христианство как «письменная религия»: «Возникновение и развитие письменности на Руси были обусловлены потребностью в изложении и распространении христианского вероучения» [24, с. 124].

2. Созданная на христианской этической и эстетической основе древнерусская словесность с ее приоритетом духовного содержания, «стройной космологической системой», «отвлеченными категориями развитого абстрактного мышления» [24, с. 125], установкой на формирование христианского мировоззрения определила систему аксиологических доминант русской литературы последующих периодов, представления о мире и человеке. Несмотря на то, что эти представления менялись с X по XIX в., в сознании Достоевского, как и других писателей, ориентированных на исследование ценностно-смысловой структуры личности, актуализируются такие значимые доминанты, как религиозно-символический метод познания действительности (умозрение), соединенный с интуитивным созерцанием идеи бытия как духовного образа (здесь речь идет о доминатах художественного метода писателя - «фантастического реализма»), аксиологический характер отношения к действительности, синтез бытового, мирского и бытийного, сакрального измерения, приоритет смысловой, а не причинно-следственной связи событий, использование слова-символа для передачи событий и артефактов духовной реальности, религиозно- 
нравственное отношение ко времени и пространству и т. д.

3. Влияние агиографической традиции на творчество Достоевского - комплексная проблема как с точки зрения аспекта исследования, так и с точки зрения методологии, учитывающей не только формат сопоставления тех или иных признаков сходства и различия и объяснения их причины, но глубинную связь на уровне особенностей сознания и ценностного отношения к действительности в контексте православной парадигмы мышления и опыта духовной жизни. Можно говорить о том, что в смене литературных формаций творчество Достоевского позволяет увидеть то духовное ядро, которое сохраняет русская классическая литература и транслирует из эпохи в эпоху в качестве культурообразующей и смыслообразующей доминанты. По справедливому замечанию М. М. Бахтина, «для того, чтобы обнаруживать эволюционную связь, нужно показать, <..> что два явления существенно связаны между собой и одно - предшествующее существенно и необходимо определяет другое - последующее» [25, с. 181182].

\section{Список литературы}

1. Палиевский П. В. Развитие русской литературы XIX - начала XX века. Панорама. СПб.: Росток, 2016. 288 с.

2. Ветловская В. Е. Поэтика «Братьев Карамазовых». Л., 1972. 198 с.

3. Кусков В. В. Мотивы древнерусской литературы в романе Ф. М. Достоевского «Братья Карамазовы» // Вестник МГУ. Серия 10: филология. 1974. Вып. 5. С. 22-28.

4. Тихомиров Б. Н. Житие великого грешника // Достоевский: Сочинения, письма, документы: словарь-справочник. СПб., 2008. C. 291-298.

5. Касаткина Т. А. Священное в повседневном: Двусоставный образ в произведениях Ф. М. Достоевского. М.: ИМЛИ РАН, 2015. $528 \mathrm{c}$.

6. Роман Ф. М. Достоевского «Братья Карамазовы»: современное состояние изучения / под. ред. Т. А. Касаткиной; Ин-т мировой лит. им. А. М. Горького РАН. М.: Наука, 2007. 835 с.

7. Ланцов А. С. «Будут все как дети божии...»: традиции житийной литературы в романе Ф. М. Достоевского «Братья Карамазовы». СПб.: Алтейя, 2012. 64 с.

8. Мочульский К. В. Достоевский: Жизнь и творчество. Paris: YMCA-Press, 1980. 561 с.

9. Фридлендер Г. М. Пушкин. Достоевский. «Серебряный век» / Российская академия наук. Институт русской литературы (Пушкинский Дом). СПб.: Наука, 1995. 524 с.

10. Гроссман Л. П. Поэтика Достоевского. М.: Гос. акад. наук, 1925. 191 с.

11. Шилова А. С., Кошечко А. Н. Агиографическая традиция в творчестве Ф. М. Достоевского (на материале «Жития Великого грешника», романа «Братья Карамазовы»): к постановке проблемы // Вест. Томского гос. пед. ун-та (TSPU Bulletin). 2019. Вып. 9. С. 128-135. DOI 10.23951/1609-624X-2019-9-128-135

12. Дорофеева Л. Г. Проблема изучения русской агиографии // Слово. ру: балтийский акцент. 2017. Т. 8, № 1. С. 11-23.

13. Достоевский Ф. М. Полное собрание сочинений: в 30 т. Л.: Наука, 1972-1986.

14. Кошечко А. Н. Экзистенциальная судьба Ф. М. Достоевского: способы отражения в слове. Томск: Изд-во ТГПУ, 2015.160 c.

15. Кошечко А. Н. «Мир с Богом» и «мир без Бога»: религиозный и атеистический типы духовности в экзистенциальной аксиологии романа Ф. М. Достоевского «Бесы» // Сибирский филол. журн. 2014. Вып. 3. С. 94-104.

16. Бердяев Н. Миросозерцание Достоевского. Харьков: Фолио, 1999. 288 с.

17. Кошечко А. Н. Формы экзистенциального сознания в творчестве Ф. М. Достоевского: дис. ... д-ра филол. наук. Томск, 2014. $312 \mathrm{c}$.

18. Ермишина К. В. Религиозная антропология. М.: Изд-во Православного Свято-Тихоновского гуманитарного университета, $2013.368 \mathrm{c}$.

19. Камедина Л. В. Текст в диалоге с читателем: опыт прочтения русской литературы в начале третьего тысячелетия. Чита: Забайкальский гос. ун-т, 2017. 178 с.

20. Лихачев Д. С. Система литературных жанров Древней Руси // Славянские литературы. Доклады советских ученых, подготовленные к V Международному съезду славистов. М.: Изд-во АН СССР, 1963. 380 с.

21. Осипов А. И. Достоевский и христианство // Библиотека «Православная беседа». URL: https://pravbeseda.ru/library/index. php?id=470\&page=book (дата обращения: 28.01.2020).

22. Соловьев В. С. Избранное / сост. А. В. Гулыги, С. Л. Кравца. М.: Сов. Россия, 1990. 496 с.

23. Кошечко А. Н. Образ Христа как духовный императив в «Дневнике писателя» Ф. М. Достоевского: к постановке проблемы об интеграции религиозного и экзистенциального типов сознания // Сибирский филол. журн. 2012. Вып. 3. С. 62-71.

24. Ужанков А. Н. Историческая поэтика древнерусской словесности. Генезис литературных формаций. М.: Изд-во Лит. инта им. М. А. Горького, 2011. 512 с.

25. Медведев П. Н. (М. М. Бахтин). Формальный метод в литературоведении. М.: Лабиринт, 1993. 207 с. 
Кошечко Анастасия Николаевна, доктор филологических наук, профессор, Томский государственный педагогический университет (ул. Киевская, 60, Томск, Россия, 634061). E-mail: Nastyk78@mail.ru.

Шилова Алина Сергеевна, аспирант, Томский государственный педагогический университет (ул. Киевская, 60, Томск, Россия, 634061). E-mail: na4arova.lina@yandex.ru.

Материал поступил в редакциию 16.03.2020.

DOI 10.23951/1609-624X-2020-3-14-21

\section{VALUE ASPECTS OF STUDYING AGIOGRAPHIC TRADITION IN CREATIVITY OF F. M. DOSTOYEVSKY: METHODOLOGICAL REFLECTION}

A. N. Koshechko, A. S. Shilova

Tomsk State Pedagogical University, Tomsk, Russian Federation

Introduction. This article presents a methodological reflection of the study of the value-semantic aspects of the representation of the hagiographic tradition in Dostoevsky's work. Analysis of the artistic anthropology of the writer, ideological searches and spiritual conflicts, which determine the peculiarities of the problem and poetry of his works, allows to see the deep connection with the hagiographic tradition in its understanding of the world and man. The spiritual experience captured in the lives for the writer is not just a genre or pictorial tool, but a deep semantic vector, anthropological and axiological dominant.

Material and methods. The material of the study is artistic and journalistic works of late creativity of F.M. Dostoevsky, the ego-documents of the writer, memories of contemporaries. The methodological basis of the study is the axiological approach, which is complex and includes cultural-historical, comparative, structural-typological, and biographical aspects.

In the system of views of F. M. Dostoevsky, questions about a person, his spiritual and moral development, value attitudes and ideals are of great importance, are reflected in artistic creation, especially in the novel The Brothers Karamazov and The Life of the Great Sinner, take a basis among the life of the writer, his religious education and religious-philosophical worldview.

Results and discussion. The representation of the hagiographic tradition is inextricably linked to the writer 's worldview, his system of values. In the system of views of F.M. Dostoevsky, questions about man, his spiritual and moral development, values and ideals are of fundamental importance, are reflected in artistic creativity, especially in the novel The Brothers Karamazov and The Life of a Great Sinner, take the basis among the life attitudes of the writer, his religious education and religious and philosophical worldview.

Conclusion. The influence of the hagiographic tradition on Dostoevsky's creativity is a complex problem both in terms of research aspect and methodology. The study should take into account the deep connection of Russian literature with Christian religious tradition. In the process of changing literary formations, Dostoyevsky 's creativity allows to see the spiritual core that Russian classical literature preserves and broadcasts from era to era as a culturalforming and meaning-forming dominant.

Keywords: Fyodor Dostoevsky, The Brothers Karamazov, The Life of a Great Sinner, A Writer's Diary, egodocuments, author, hagiographic tradition, axiology, values, value and worldview position, Christianity, Orthodoxy, Russian culture, morality, spirituality, holiness, axiological approach.

\section{References}

1. Paliyevskiy P. V. Razvitiye russkoy literatury XIX - nachala XX veka. Panorama [The development of Russian literature of the twentieth - early twentieth century. Panorama]. Saint Petersburg, Rostok Publ., 2016. 288 p. (in Russian).

2. Vetlovskaya V. E. Poetika "Brat'ev Karamazovykh" [Poetics of "The Brothers Karamazov"]. Leningrad, 1972.198 p. (in Russian).

3. Kuskov V. V. Motivy drevnerusskoy literatury v romane F. M. Dostoyevskogo "Brat'ya Karamazovy" [Motives of Old Russian Literature in the novel by F. M. Dostoevsky "The Brothers Karamazov"]. Vestnik MGU. Seriya 10: filologiya, 1974, vol. 5, pp. 22-28 (in Russian).

4. Tikhomirov B. N. Zhitiye velikogo greshnika [The life of the great sinner]. In: Dostoyevskiy: Sochineniya, pis'ma, dokumenty: Slovar'-spravochnik [Dostoevsky: Works, letters, documents: dictionary]. Saint Petersburg, 2008. Pp. 291-298 (in Russian).

5. Kasatkina T. A. Svyashchennoye v povsednevnom: Dvusostavnyy obraz v proizvedeniyakh F. M. Dostoyevskogo [The sacred in the everyday: A two-part image in the works of F. M. Dostoevsky]. Moscow, IMLI RAS Publ., 2015. 528 p. (in Russian).

6. Roman F. M. Dostoyevskogo "Brat'ya Karamazovy": sovremennoye sostoyaniye izucheniya. Pod. red. T. A. Kasatkinoy [Novel by F. M. Dostoevsky “The Brothers Karamazov”: current state of study. Edited by T. A. Kasatkina]. Moscow, Nauka Publ., 2007. 835 p. (in Russian). 
7. Lantsov A. S. "Budut vse kak deti bozhii...": traditsii zhitiynoy literatury v romane F. M. Dostoyevskogo "Brat'ya Karamazovy" ["They will all be like God's children...": traditions of everyday literature in the novel by F. M. Dostoevsky "The Brothers Karamazov"]. Saint Petersburg, Alteyya Publ., 2012. 64 p. (in Russian).

8. Mochul'skiy K. V. Dostoyevskiy: Zhizn'i tvorchestvo [Dostoevsky: Life and work]. Paris, YMCA-Press Publ., 1980. 561 p. (in Russian).

9. Fridlender G. M. Pushkin. Dostoyevskiy. "Serebryanyy vek" [Pushkin. Dostoevsky. "Silver Age”]. Rossiyskaya akademiya nauk. Institut russkoy literatury (Pushkinskiy Dom) [The Russian Academy of Sciences. Institute of Russian Literature (Pushkin House)]. Saint Petersburg, Nauka Publ., 1995. 524 p. (in Russian).

10. Grossman L. P. Poetika Dostoyevskogo [Poetics of Dostoevsky]. Moscow, Russian Academy of Sciences Publ., 1925.191 p. (in Russian).

11. Shilova A. S., Koshechko A. N. Agiograficheskaya traditsiya v tvorchestve F. M. Dostoyevskogo (na materiale "Zhitiya Velikogo greshnika", romana "Brat'ya Karamazovy"): k postanovke problem [Hagiographic tradition in the work of F. M. Dostoevsky (the study of "The Life of the Great Sinner", the novel "The Brothers Karamazov"): to the statement of problems]. Vestnik Tomskogo gosudarstvennogo pedagogicheskogo universiteta - TSPU Bulletin, 2019, vol. 9, pp. 128-135 (in Russian). DOI 10.23951/1609624X-2019-9-128-135

12. Dorofeyeva L. G. Problema izucheniya russkoy agiografii [The problem of studying Russian hagiography]. Slovo.ru: baltiyskiy aktsent - Slovo.ru: Baltic Accent, 2017, vol. 8, no. 1, pp. 11-23 (in Russian).

13. Dostoyevskiy F. M. Polnoye sobraniye sochineniy: $v 30$ t. [Complete collection of works: in 30 volumes]. Leningrad, Nauka Publ., 1972-1986 (in Russian).

14. Koshechko A. N. Ekzistentsial'naya sud'ba F. M. Dostoyevskogo: sposoby otrazheniya v slove [The existential fate of F. M. Dostoevsky: ways of reflection in the word]. Tomsk, TSPU Publ., 2015. 160 p. (in Russian).

15. Koshechko A. N. "Mir s Bogom” i "mir bez Boga”: religioznyy i ateisticheskiy tipy dukhovnosti v ekzistentsial'noy aksiologii romana F. M. Dostoevskogo "Besy" ["Peace with God" and "Peace without God": religious and atheistic types of spirituality in the existential axiology of the novel by F. M. Dostoevsky "Demons"]. Sibirskiy filologicheskiy zhurnal - Siberian Journal of Philology, 2014, vol. 3, pp. 94-104 (in Russian).

16. Berdyayev N. Mirosozertsaniye Dostoyevskogo [The Worldview of Dostoevsky]. Harkov, Folio Publ., 1999. 288 p. (in Russian).

17. Koshechko A. N. Formy ekzistentsial'nogo soznaniya v tvorchestve F. M. Dostoyevskogo. Dis. dokt. filol. nauk [Forms of existential consciousness in the work of F. M. Dostoevsky. Diss. of doct. of philol. sci.]. Tomsk, 2014. 312 p. (in Russian).

18. Ermishina K. V. Religioznaya antropologiya [Religious anthropology]. Moscow, St. Tikhon's Orthodox University Publ., 2013. 368 p. (in Russian).

19. Kamedina L. V. Tekst $v$ dialoge s chitatelem: opyt prochteniya russkoy literatury $v$ nachale tret'ego tysyacheletiya [The text in dialogue with the reader: the experience of reading Russian literature at the beginning of the third millennium]. Chita, Transbaikal State University Publ., 2017. 178 p. (in Russian).

20. Likhachev D. S. Sistema literaturnykh zhanrov Drevney Rusi [The system of literary genres of Ancient Russia]. Slavyanskiye literatury. Doklady sovetskikh uchenykh, podgotovlennye k V Mezhdunarodnomu s"ezdu slavistov [Slavic literature. Reports of Soviet scientists prepared for the V International Congress of Slavists]. Moscow, Academy of Sciences USSR Publ., 1963. 380 p. (in Russian).

21. Osipov A. I. Dostoyevskiy i khristianstvo [Dostoevsky and Christianity]. Biblioteka "Pravoslavnaya beseda" [Library "Orthodox Conversation"] (in Russian). URL: https://pravbeseda.ru/library/index.php?id=470\&page=book (accessed 28 January 2020).

22. Solov'ev V. S. Izbrannoye. Sost. A. V. Gulygi, S. L. Kravtsa [The Selected. Compilers A. V. Gulygi, S. L. Kravtsa]. Moscow, Sov. Rossiya Publ., 1990. 496 p. (in Russian).

23. Koshechko A. N. Obraz Khrista kak dukhovnyy imperativ v "Dnevnike pisatelya" F. M. Dostoyevskogo: k postanovke problemy ob integratsii religioznogo i ekzistentsial'nogo tipov soznaniya [The image of Jesus Christ as a spiritual imperative in "A Writer's Dairy" by F. M. Dostoevsky: on stating the problem of integrating the religious (orthodox) and the existential type of consciousness]. Sibirskiy filologicheskiy zhurnal - Siberian Journal of Philology, 2012, vol. 3, pp. 62-71 (in Russian).

24. Uzhankov A. N. Istoricheskaya poetika drevnerusskoy slovesnosti. Genezis literaturnykh formatsiy [Historical poetics of ancient Russian words. Genesis of literary formations]. Moscow, M. A. Gorky Literary Institute Publ., 2011. 512 p. (in Russian).

25. Medvedev P. N. (M. M. Bakhtin). Formal'nyy metod v literaturovedenii [Formal method in literature]. Moscow, Labirint Publ., 1993. 207 p. (in Russian).

Koshechko A. N., doctor of philology, professor, Tomsk State Pedagogical University (ul. Kiyevskaya, 60, Tomsk, Russian Federation, 634061). E-mail: Nastyk78@mail.ru

Shilova A. S., graduate student, Tomsk State Pedagogical University (ul. Kiyevskaya, 60, Tomsk, Russian Federation, 634061). E-mail: na4arova.lina@yandex.ru 